\section{Mortalidade Infantil no Estado de \\ São Paulo, 1999: uma análise das \\ causas múltiplas de morte a partir \\ de componentes principais}

\author{
Infant Mortality in the State of São \\ Paulo, 1999: principal components \\ analysis of multiple causes of death
}

\section{Carla Jorge Machado}

Departamento de Demografia do Centro de Desenvolvimento e Planejamento Regional (Cedeplar)

Universidade Federal de Minas Gerais

Av. Augusto de Lima, 1376/sl. 908

30190-003 Belo Horizonte - MG

carla@cedeplar.ufmg.br

\section{Resumo}

Objetivos: Descrever o padrão da mortalidade infantil no Estado de São Paulo em 1999, segundo causas múltiplas de morte, bem como comparar os dados de causas básicas e múltiplas de óbito. Material e Métodos: Utilizou-se dados de 12.793 óbitos infantis para 1999, obtidos da Fundação Sistema Estadual de Análise de Dados (Seade). As causas de óbito haviam sido codificadas de acordo com a Décima Classificação Internacional de Doenças e foram categorizadas em 28 grupos de causas. Para análise das causas múltiplas de morte, fez-se uma tabulação simples das mesmas e utilizou-se a análise de componentes principais, a fim de se obter os principais grupos de enfermidades que conduziram ao óbito. Resultados: As principais causas múltiplas de óbito foram os transtornos respiratórios e cardiovasculares específicos do período perinatal $(24,2 \%$ do total de causas múltiplas), os transtornos relacionados com a duração da gestação e com o crescimento fetal $(20,2 \%)$, as malformações congênitas $(8,6 \%)$ e as infecções perinatais (7,6\%). A análise de componentes principais revelou três componentes interpretáveis, relativos aos óbitos devidos a causas de origem "pós-neonatais, infecciosas, redutíveis", às "complicações de procedimentos e causas externas" e aos "transtornos perinatais não associados ao baixo peso e/ou à imaturidade". Conclusão: A sistematização das causas múltiplas de morte em conjuntos de enfermidades permitiu analisá-las e entender como se associavam, desdobrando-se em manifestações de doenças que conduziram à morte, o que não é possível através da análise segundo causas básicas. Foi possível, então, observar com maior clareza os conjuntos de enfermidades que levaram ao óbito, o que é mais elucidativo para fins de Saúde Pública, visando a prevenção das doenças em suas diversas fases de causação.

Palavras-chave: Mortalidade infantil. Causas múltiplas de morte. Análise de componentes principais. 
Abstract

Objective: To describe infant mortality in the State of São Paulo, in 1999, based on multiple causes of death and to compare data from underlying and multiple causes of death. Methods: Data came from 12,793 infant death records in 1999, of Seade Foundation (State Data Analysis System Foundation). Causes of death were coded according to the Tenth Revision of the International Statistical Classification of Diseases and Related Problems and were classified into 28 meaningful groups for the purpose of this article. In order to analyze multiple causes of death, simple frequencies were used in addition to principal components analysis to obtain the main groups of causes that contributed to death. Results: The most frequent multiple causes of death were respiratory and cardiovascular diseases of the perinatal period $(24.2 \%$ of all multiple causes), diseases related to growth and maturity of the fetus and the newborn (20.2\%), congenital malformations $(8.6 \%)$ and perinatal infections (7.6\%). Principal components analysis revealed three major interpretable components: "post-neonatal, infectious and avoidable deaths", "complications of procedures and external causes" and "perinatal disorders, not related to low birth weight and/or immaturity". Conclusion: By using principal components analysis it was easier to understand how the multiple causes were associated. This is more interesting for Public Health purposes, because it may help clarify the steps in disease causation.

Keywords: Infant mortality. Multiple causes of death. Principal components analysis.

\section{Introdução}

A causa de morte representa uma das mais importantes formas de análise da mortalidade $^{1}$. Tradicionalmente, as estatísticas de mortalidade referem-se apenas à causa básica $^{2}$, mas há limitações em relação ao seu uso para a descrição da mortalidade, pois na seleção desta são excluídas as chamadas causas associadas, que incluem as causas conseqüenciais, importantes para a compreensão da cadeia mórbida que leva diretamente ao óbito, bem como as afecções presentes no momento da morte, porém não relacionadas com a causa básica. Deste modo, não se depreende o quadro global do processo mórbido. No caso das mortes violentas, analogamente, omite-se a natureza da lesão, preterida aos dados sobre as circunstâncias da sua ocorrência ${ }^{1}$.

A preocupação com o determinismo imposto pelo conceito de causa básica emergiu a partir da constatação de que cada vez mais os indivíduos vinham falecendo em decorrência de mais de uma doença, conseqüência tanto da crescente prevalência de doenças crônicas degenerativas, cuja etiologia é mais complexa, quanto da existência de inadequadas condições de moradia nas áreas menos desenvolvidas, produzindo processos mórbidos que se manifestam através da associação de doenças infecciosas e parasitárias e outras doenças ou lesões ${ }^{2}$. Desta forma, a tabulação das causas múltiplas permite discriminar os principais aglomerados de causas de óbito e levar em conta os mais freqüentes processos mórbidos que podem ser sinergísticos ou aditivos ${ }^{3}$. Atente-se que o modelo de causa básica foi desenvolvido quando a problemática elementar na Saúde Pública eram as doenças epidêmicas: quando uma morte ocorria, sua causa podia ser usualmente abstraída como uma condição única que levava à morte ${ }^{4}$. Tratava-se então de um modelo de mortalidade humana baseado na concepção da doença e da morte como processos de "choque" segundo os quais estes fenômenos de interesse manifestar-se-iam simultaneamente. Com a transição epidemiológica, no entanto, o foco da 
Saúde Pública passou a ser também, no caso do indivíduo adulto, as doenças crônicas degenerativas, cuja etiologia é mais complexa. No caso da mortalidade infantil, a transição epidemiológica está levando a uma redução das doenças infecciosas com relação às de origem perinatais, cuja etiologia é também de maior complexidade. Emergem, por conseguinte, as deficiências do modelo de causa básica. Uma alternativa sugerida seria a de se restabelecer um "conceito de mortalidade humana", que seria suficientemente abrangente para permitir que qualquer morte pudesse ter mais do que apenas uma causa; admitir que a causa de morte operasse durante um período de tempo; e refletir a possibilidade das doenças poderem interagir com as características do hospedeiro ${ }^{4}$. Ou seja, um novo modelo, mais realista, consideraria a morte como um evento causado por condições múltiplas.

A causa básica dá origem a uma sucessão de afecções, que são as chamadas causas conseqüenciais, a última das quais é chamada imediata ou direta. Outras causas que não entram na cadeia iniciada pela básica são as contributivas. As afecções conseqüenciais e as contributivas constituem o que se chama de causas associadas. As estatísticas de mortalidade por causas múltiplas são as obtidas pela classificação das básicas e das associadas, existentes nos atestados e apresentadas segundo estas características ${ }^{5}$. $\mathrm{O}$ objetivo deste trabalho é descrever o panorama da mortalidade infantil no Estado de São Paulo, em 1999, segundo causas múltiplas de morte.

\section{Material e Métodos}

Utilizou-se dados de óbitos infantis que ocorreram no ano de 1999, de residentes do Estado de São Paulo, obtidos da Fundação Seade, totalizando 12.793 óbitos. Todas as causas de morte foram arquivadas em campos específicos distintos, por meio de 'string', que reproduzia tanto a linha quanto a posição na linha em que as causas tivessem sido informadas no Modelo Internacional de Atestado Médico ${ }^{6}$. Para a análise dos dados, inicialmente todas as causas foram consideradas dentro de seus grandes grupos, com exceção das perinatais (Capítulo XVI da CID-10), que foram consideradas em seus 10 subgrupos, ou seja, em suas respectivas categorias de 3 caracteres. Isto se justifica pelo fato de que a maioria dos óbitos é neonatal (8.819 óbitos, ou $69 \%$ do total). Obteve-se 28 grupos de causas de morte, que foram transformados em variáveis binárias ('0' caso a criança não tivessemencionada a causa de morte especificada; ' 1 ' caso contrário), as quais foram categorizadas, da seguinte forma:

1) Algumas doenças infecciosas e parasitárias: códigos A00 a B99

2) Neoplasias (tumores): códigos $\mathrm{C} 00$ a D48

3) Doenças do sangue e órgãos hematopéticos e transtornos imunitários: códigos D50 a D69

4) Doenças endócrinas, nutricionais e metabólicas: códigos E00 a E90

5) Transtornos mentais e comportamentais: códigos F00 a F99

6) Doenças do sistema nervoso: códigos G00 a G99

7) Doenças dos olhos e anexos: códigos H00 a H59

8) Doenças do ouvido e da apófise mastóide: códigos H60 a H95

9) Doenças do aparelho circulatório: códigos I00 a I99

10) Doenças do aparelho respiratório: códigos J00 a J99

11) Doenças do aparelho digestivo: códigos K00 a K93

12) Doenças da pele e do tecido subcutâneo: códigos L00 a L99

13) Doenças do sistema osteomuscular e do tecido conjuntivo: códigos M00 a M99

14) Doenças do aparelho geniturinário: códigos N00 a N99

15) Malformações congênitas, deformidades e anomalias cromossômicas: códigos Q00 a Q99

16) Sintomas, sinais e achados anormais de exames clínicos e de laboratório não classificados em outra parte: códigos R00 a R99

17) Lesões, envenenamentos e algumas outras conseqüências de causas externas: código S00 a T98 
18) Causas externas de morbidade e mortalidade: códigos V001 a Y98

19) Feto e recém-nascido afetados por fatores maternos e por complicações da gravidez, do trabalho de parto e do parto: códigos P00 a P04

20) Transtornos relacionados com a duração da gestação e com o crescimento fetal: códigos P05 a P08

21) Traumatismo de parto: códigos P10 a P15

22) Transtornos respiratórios e cardiovasculares específicos do período perinatal: códigos P20 a P29

23) Infecções específicas do período perinatal: códigos P35 a P39

24) Transtornos hemorrágicos e hematológicos do feto e do recém-nascido: códigos P50 a P61

25) Transtornos endócrinos e metabólicos transitórios específicos do feto e do recém-nascido: códigos P70 a P74

26) Transtornos do aparelho digestivo do feto e do recém-nascido: códigos P75 a P78

27) Afecções comprometendo o tegumento e a regulação térmica do feto e do recém-nascido: códigos P80 a P83

28) Outros transtornos originados no período perinatal: códigos P90 a P96

Desta forma, para cada criança, cada causa categorizada foi transformada em uma variável binária. Evitou-se, assim, a duplicação ou multiplicação de um mesmo diagnóstico, segundo a categoria utilizada no estudo $^{6,7}$. A Classificação Internacional de Doenças atribui um código a cada diagnóstico; o que ocorre freqüentemente é que os atestados apresentam esse pormenor, e se fossem codificados todos os diagnósticos poderia ocorrer multiplicação ou, mais comumente, duplicação de uma mesma causa, dado que o médico poderia ter especificado formas evolutivas da mesma doença ${ }^{5}$.

Tabulou-se as causas básicas de morte em uma análise inicial e em seguida as causas múltiplas para as 28 causas, a fim de se comparar as freqüências e observar se uma determinada causa havia sido declarada mais comumente como causa básica ou como causa associada. Foram listadas neste trabalho as 15 causas mais freqüentes. Para estas 15, utilizou-se a razão entre a freqüência de causas múltiplas e a freqüência de causas básicas (razão M/B) para verificar se esta era superior à unidade.

Em seguida, para as causas múltiplas de óbito mais freqüentes dentre as 15 listadas, tabulou-se categorias mais específicas de causas (a quatro caracteres, por exemplo) explicitando-as mais pormenorizadamente, a fim de se obter um panorama mais detalhado da morbi-mortalidade nesta população.

Para o estudo da ocorrência conjunta das causas, utilizou-se a análise de componentes principais, que permite transformar linearmente o conjunto de variáveis originais em um conjunto substancialmente menor de variáveis não correlacionadas, as quais representam a maioria da informação contida no conjunto original de variáveis ${ }^{8}$. A análise de componentes principais parte da ausência de um modelo estatístico subjacente na divisão das variáveis observadas, baseando-se nas propriedades da variância máxima dos componentes principais. Difere da análise fatorial nesse sentido, uma vez que a análise fatorial parte de um modelo estatístico prévio que subdivide a variância total ${ }^{9}$. Na análise de componentes principais utilizou-se a variável "idade ao morrer", em número de dias, como uma variável contínua. Foi possível calcular esta idade uma vez que se possuía a data de nascimento e a data do óbito. Para 48 crianças $(0,37 \%$ do total) não havia informação da data de nascimento ou da data de óbito, e estas crianças foram excluídas da análise de componentes principais.

A coordenada de uma dada variável ao longo de um eixo é o coeficiente de correlação entre essa variável e o fator (coeficiente de saturação). O quadrado de sua coordenada é igual à qualidade da representação de uma variável e é proporcional a sua contribuição para a inércia do eixo. A interpretação do fator é baseada na síntese das variáveis mais ligadas ao eixo, ou seja, com maior coeficiente de correlação ${ }^{9}$. Assim, utilizou-se os coeficientes de saturação para guiar a interpretação dos componentes ob- 
tidos. Além disso, uma das principais questões na análise de componentes principais é o critério de escolha do número de componentes a ser mantido ${ }^{9}$. Neste trabalho utilizou-se o critério baseado no número de fatores interpretáveis recomendado por diversos autores ${ }^{9}$. Este critério propõe conservar os fatores para os quais sabe-se de forma clara dar uma interpretação ou significado conceitual.

Para as análises estatísticas, utilizou-se o software STATA, versão 6.

\section{Resultados}

Após categorizadas as 28 causas de óbito, obteve-se 28.182 causas múltiplas de morte, distribuídas em 12.793 óbitos. A média foi de 2,2 diagnósticos para cada óbito, e a moda foi de dois diagnósticos para cada óbito. O número máximo de diagnósticos foi sete, para duas crianças.

\section{A mortalidade segundo causas básicas e segundo causas múltiplas}

A Tabela 1 apresenta o número de menções das causas de morte, enquanto básicas e enquanto múltiplas para as 15 causas mais freqüentes. Encontra-se ainda na Tabela 1 a razão entre estas duas quantidades (razão $\mathrm{M} / \mathrm{B})$.

As causas básicas que mais se destacaram foram os transtornos respiratórios e cardiovasculares do recém-nascido (38,3\%), seguidas das malformações congênitas $(15,2 \%)$, das doenças do aparelho respiratório $(8,8 \%)$ e das infecções perinatais $(8,1 \%)$, somando $70,4 \%$ do total de causas básicas.

No caso das causas múltiplas, as quatro principais causas de morte somam $60,6 \%$ de todas as causas múltiplas. Destas, os transtornos respiratórios e cardiovasculares específicos do período perinatal foram a causa mais freqüente, com $24,2 \%$ de todas as

Tabela 1 - Número e proporção de causas básicas e causas múltiplas e razão "número de causas múltiplas/ número de causas básicas" População do Estado de São Paulo de menores de um ano, 1999.

Table 1 - Number and proportion of underlying causes according to the total of underlying causes and multiple causes, and "number of multiple causes/number of underlying causes" ratio Population of infants of the State of São Paulo, 1999.

\begin{tabular}{|c|c|c|c|c|c|c|}
\hline \multirow[b]{2}{*}{ Causas de Morte } & \multicolumn{2}{|c|}{ Básicas } & \multicolumn{3}{|c|}{ Múltiplas } & \multirow[b]{2}{*}{$M / B$} \\
\hline & No & $\%$ & No & $\%^{(1)}$ & $\%^{(2)}$ & \\
\hline Doenças infecciosas e parasitárias (códigos A00-B99) & 731 & 5,7 & 1473 & 5,2 & 11,5 & 2,0 \\
\hline Endócrinas/nutricionais/metabólicas (códigos E00-E90) & 185 & 1,4 & 611 & 2,2 & 4,8 & 3,3 \\
\hline Doenças do sistema nervoso (códigos G00-G99) & 248 & 1,9 & 450 & 1,6 & 3,5 & 1,8 \\
\hline Doenças do aparelho circulatório (códigos 100-199) & 116 & 0,9 & 416 & 1,5 & 3,3 & 3,6 \\
\hline Doenças do aparelho respiratório (códigos J00-J99) & 1125 & 8,8 & 2044 & 7,3 & 16,0 & 1,8 \\
\hline Malformações congênitas/anom./deform.(códigos Q00-Q99) & 1949 & 15,2 & 2425 & 8,6 & 19,0 & 1,2 \\
\hline Sintomas/sinais/achados de exames (códigos R00-R99) & 421 & 3,3 & 1469 & 5,2 & 11,5 & 3,5 \\
\hline Lesões/envenen./conseq. causas externas (códigos S00-T98) & 0 & 0,0 & 427 & 1,4 & 3,3 & NA \\
\hline Causas externas de morbidade e de mortalidade (códigos V01-Y98) & 309 & 2,4 & 580 & 4,5 & 4,5 & 1,9 \\
\hline $\begin{array}{l}\text { Feto e RN afetados por fatores maternos e complicações } \\
\text { gravidez/parto (códigos P00-P04) }\end{array}$ & 460 & 3,6 & 768 & 2,7 & 6,0 & 1,7 \\
\hline Transt. duração gest./crescimento fetal (códigos P05-P08) & 415 & 3,2 & 5700 & 20,2 & 44,6 & 13,7 \\
\hline Transt. respir./cardio período perinatal (códigos P20-P29) & 4897 & 38,3 & 6834 & 24,2 & 53,4 & 1,4 \\
\hline Infecções específicas período perinatal (códigos. P35-P39) & 1035 & 8,1 & 2138 & 7,6 & 16,7 & 2,1 \\
\hline Transt. hemorr./hematológicos feto/rn (códigos P50-P61) & 203 & 1,6 & 590 & 2,1 & 4,6 & 2,9 \\
\hline Outros transtornos perinatais (códigos P90-P96) & 279 & 2,2 & 1081 & 3,8 & 8,5 & 3,9 \\
\hline Demais & 420 & 3,4 & 1176 & 1,9 & NA & 2,8 \\
\hline Total & 12793 & 100,0 & 28182 & 100,0 & & 2,2 \\
\hline
\end{tabular}

Fonte: Fundação SEADE, 1999/ Source: SEADE Foundation, 1999

Nota: (1) proporção em relação ao total de causas múltiplas; (2) proporção em relação ao total de óbitos.

Note: (1) proportion in relation to total number of multiple causes; (2) proportion in relation to total number of deaths. 
causas múltiplas, seguidos dos transtornos relacionados com a duração da gestação e com o crescimento fetal $(20,2 \%)$, das malformações congênitas $(8,6 \%)$ e das infecções perinatais $(7,6 \%)$. Em relação ao total de crianças, $53,4 \%$ destas (6.834 das 12.793 ) tiveram algum transtorno respiratório e/ou cardiovascular específico do período perinatal declarado; essas proporções foram de $44,6 \%$ e de $19 \%$ para os transtornos relacionados com a duração da gestação ou com o crescimento fetal.

Já a última coluna da Tabela 1 mostra a razão entre o número de vezes em que uma causa foi mencionada como básica e em qualquer posição (básica ou associada). Se uma causa fosse unicamente registrada como básica, a razão seria um. Qualquer valor acima de um indica informação adicional, perdida sob o enfoque de causa básica. Assim, todas as causas que figuram na Tabela 1 foram alguma vez registradas como causa associada. Os transtornos relacionados ao crescimento fetal ou duração da gestação apresentaram razão M/B de 13,7, ou seja, o número de vezes que se registra esta causa em qualquer posição é 13,7 vezes maior do que o número de vezes que se registra esta causa como básica. Já as malformações tiveram uma razão M/B de apenas 1,2.

As seis causas múltiplas mais freqüentes, que representam, cada uma, mais de $10 \%$ do total das causas múltiplas, foram desagregadas, conforme está mostrado na Tabela 2. As porcentagens são em relação ao total de óbitos. As "outras afecções respiratórias do recém-nascido”, rubrica que inclui a apnéia do recém-nascido e as atelectasias do recém-nascido, foram as que mais acometeram esta população (3.502 crianças, $27,4 \%$ do total). A prematuridade constituiuse na segunda causa de óbito mais freqüente, pois 3.053 crianças (quase $24 \%$ do total) tiveram pelo menos uma menção de prematuridade em seu certificado de óbito, seguida pelo recém-nascido de baixo peso (códigos P070 e P071) (2.662 crianças ou 20,8\% do total). Note-se ainda a participação importante das doenças de caráter infeccioso. As septicemias bacterianas do recém-nascido, mais comuns no período neonatal, acometeram quase $15 \%$ do total (1.897 crianças) As gripes e pneumonias, e outras doenças das vias aéreas superiores, levaram ao óbito de 1.363 crianças no primeiro ano de vida. Destaque-se ainda as doenças infecciosas intes-

Tabela 2 - Número e proporção de causas múltiplas em relação ao total de óbitos.

Table 2 - Number and proportion of multiple causes in relation to the total number of deaths.

\begin{tabular}{lrr}
\hline Causas de Morte & Número & $\%$ \\
\hline Doenças infecciosas intestinais (códigos A00-A09) & 421 & 3,3 \\
Outras doenças bacterianas (códigos A30-A49) & 1112 & 8,7 \\
Outras septicemias (códigos A41) & 1072 & 8,4 \\
Influenza [gripe] e pneumonia e outras infecções agudas das vias aéreas superiores & 1363 & 10,7 \\
(códigos J10-J22) & & \\
Malformações congênitas do sistema nervoso (códigos Q00-Q07) & 439 \\
Malformações congênitas do aparelho circulatório (códigos Q20-Q28) & 1027 & 8,0 \\
Outras malformações congênitas e as anomalias cromossômicas não classificadas em outra & 731 & 5,7 \\
parte (códigos Q80-Q99) & 2662 & 20,8 \\
Recém-nascidos de peso muito baixo ou outros recém-nascidos de peso baixo & \\
(códigos P070 e P071) & 3053 & 23,9 \\
Imaturidade extrema e outros recém-nascidos de pré-termo (cód. P072 e P073) & 1736 \\
Hipóxia intrauterina ou asfixia ao nascer (códigos P200-P219) & 13,6 \\
Desconforto (angústia) respiratório(a) do recém-nascido (códigos P22) & 1850 \\
Pneumonia congênita (códigos P23) & 70,5 \\
Outras afecções respiratórias originadas no período perinatal (códigos P28) & 5,5 \\
Septicemia bacteriana do recém-nascido (códigos P36) & 3502 & 27,4 \\
\hline
\end{tabular}

Fonte: Fundação SEADE, 1999/Source: SEADE Foundation, 1999. 
tinais e as outras doenças bacterianas (dentre as quais a septicemia é responsável por $96,4 \%$ dos óbitos). As septicemias acometeram mais de 1.000 crianças ( $8,4 \%$ do total).

\section{Análise de componentes principais}

A Tabela 3 revela os resultados da análise segundo componentes principais, a qual mostrou que $11,8 \%$ da variação foi explicada pelo primeiro componente, que contrasta, essencialmente, dois grupos de causas de óbito: (1) as doenças respiratórias e as infecciosas e parasitárias com (2) os transtornos do feto e do recém-nascido relacionados à duração da gestação e ao crescimento fetal, e os transtornos respiratórios e cardiovasculares do período perinatal. A interpretação é a seguinte: à medida que um recém-nascido tenha vindo a falecer de uma das duas pri-

Tabela 3 - Coeficientes de saturação das causas de morte e dos grupos de idade em relação a 3 fatores (critério de fatores interpretáveis).

Table 3 - Factor loadings of causes of death and age groups in relation to 3 factors (criterion of interpretable factors).

\begin{tabular}{|c|c|c|c|}
\hline Causas de Morte & $\begin{array}{l}\text { Pós-neonatais, } \\
\text { infecciosas } \\
\text { redutíveis } \\
(3,4)^{(a)}(11,8 \%)^{(b)}\end{array}$ & $\begin{array}{c}\text { Complicações de } \\
\text { procedimentos } \\
\text { e causas } \\
\text { externas } \\
(2,0)^{(a)}(6,8 \%)^{(b)}\end{array}$ & $\begin{array}{c}\text { Transtornos } \\
\text { perinatais não } \\
\text { associados ao } \\
\text { baixo peso e/ou } \\
\text { prematuridade } \\
(1,3)^{(a)}(4,5 \%)^{(b)}\end{array}$ \\
\hline
\end{tabular}

Algumas doenças infecciosas e parasitárias

$0,572^{*}$

$-0,325$

(códigos A00-B99)

Sangue/órgãos hematopoéticos/transtornos

imunitários (códigos D50-D69)

Endócrinas/nutricionais/metabólicas (códigos E00-E90)

0,266

Doenças do sistema nervoso (códigos G00-G99)

0,420

0,274

Doenças do aparelho circulatório (códigos 100-199)

0,287

Doenças do aparelho respiratório (códigos J00-J99)

$0,634^{*}$

Malformações congênitas/deformidades/anomalias crom. (códigos Q00-Q99)

Sintomas/sinais/achados anormais de exames (códigos R00-R99)

Lesões/envenenamentos/conseqüências de causas externas (códigos S00-T98)

Causas externas de morbidade e mortalidade

(códigos V01-Y98)

Transtornos da duração gestação / crescimento fetal (códigos P05-P08)

Transtornos respiratórios/cardiov. do período perinatal (códigos P20-P29)

Infecções específicas do período perinatal

(códigos P35-P39)

Transtornos hematológicos e hemorrágicos do feto e do rn (códigos P50-P61)

Transtornos endócrinos/metabólicos transitórios

específicos do feto e do rn (códigos P70 a P74)

Transtornos do aparelho digestivo do feto ou do rn

(códigos P75-P78)

Outros transtornos originados no período perinatal

0,395

0,254

$0,870^{*}$
$0,263 \quad 0,883^{*}$

(códigos P90-P96)

Idade do óbito em número de dias

$-0,637^{*}$

$-0,727^{*}$

$-0,277$

$-0,361$

$0,607^{*}$

0,447

0,309

$0,512^{*}$

0,411

Notas: (a) Autovalores; (b) Porcentagem da variância explicada pelo fator; *Coeficientes de saturação cujos módulos são maiores do que 0,50; Coeficientes de saturação cujos módulos são menores do que 0,25 foram suprimidos.

Notes: (a) Eigenvalues; (b) Percentage of variance explained by the factor; Factor loadings whose modules were higher than 0.,50; Factor loadings whose modules were less than $0 ., 25$ were not shown. 
meiras causas de morte - grupo 1 - seu escore relativo ao primeiro componente tende a ser bastante alto. Este resultado também indica que a ocorrência conjunta destas duas causas de óbito é um fato relativamente comum quando se possui escores elevados neste primeiro componente. Por exemplo, das crianças cujos escores estavam entre os $10 \%$ maiores (1.274 crianças), $39,9 \%$ (508 crianças) tiveram a menção de ambas as causas de óbito. Na população como um todo, esta proporção foi significativamente inferior, 5,6\%, que corresponde a óbitos de 721 crianças. Além disso, este componente contrasta óbitos neonatais e pós-neonatais. Para crianças cujos escores estavam entre os $10 \%$ maiores (1.274 óbitos), a proporção de óbitos pós-neonatais foi de 99,7\% (1.270 óbitos), sendo esta de 31,1\% (3.974 óbitos) na população como um todo. Pode-se analogamente dizer que possuir um escore bastante baixo neste componente implica, quase necessariamente, ter mencionado no certificado de óbito os transtornos relacionados à gestação e ao crescimento fetal e os transtornos respiratórios/cardiovasculares do período perinatal. Na população como um todo, $33,8 \%$ do total de recém-nascidos (4.328 crianças) tiveram ambas as causas mencionadas, e para as crianças com escores entre os $10 \%$ inferiores ( 1.275 crianças), uma proporção significativamente maior (93,5\% do total) teve ambas as causas mencionadas (1.192). Na denominação deste componente, pelo fato de as variáveis com coeficiente de saturação positivos serem de origem infecciosa, de estas enfermidades poderem ser redutíveis, e de serem muito comuns no período pós-neonatal, este primeiro componente será chamado de "pósneonatais, infecciosas, redutíveis".

O segundo componente explica $6,8 \%$ da variação total. Um escore alto neste componente significa que quase sempre a criança terá duas causas de óbito codificadas: as lesões e envenenamentos e/ou conseqüências de causas externas, e alguma causa externa de morbidade e mortalidade. No total, das 427 crianças que tiveram estas causas declaradas conjuntamente (3,3\% do total), 422 des- tas tinham escores entre os $10 \%$ superiores ( $34,7 \%$ de 1.218 crianças). Note-se que as "complicações de cuidados médicos e cirúrgicos, não classificadas em outra parte” (códigos T80-T88) e as "complicações de assistência médica e cirúrgica” (códigos Y40-Y88) foram causas de óbito substancialmente declaradas nestes dois capítulos (para 150 e 268 óbitos respectivamente; em 150 vezes foram declaradas conjuntamente). Este segundo componente será chamado de "complicações de procedimentos e causas externas".

O terceiro componente explica $4,5 \%$ da variabilidade total e é caracterizado, principalmente, pela menção de infecções perinatais. Das 2.138 crianças que tiveram menção desta causa de óbito (16,7 \% do total), 2058 tinham escores entre os $30 \%$ superiores (53,3\% de 3869 crianças). Este componente também capta outras causas de óbito mencionadas em menor freqüência no Capítulo XVI, mas note-se que possuir um escore baixo neste componente implica que os transtornos respiratórios e cardiovasculares do período perinatal, muito provavelmente foram mencionados como uma das afecções que levaram ao óbito: das 3.982 crianças cujos escores estavam entre os $30 \%$ mais baixos, 3.844 tiveram menção de algum transtorno respiratório ou cardiovascular do período perinatal-96,5\% do total-e na população esta proporção foi de 53,4\% (6.834 óbitos). Este componente será denominado "transtornos perinatais não relacionados ao baixo peso e/ou à imaturidade”.

\section{Discussão}

Neste trabalho utilizou-se as causas básicas e múltiplas de óbito para estudar a mortalidade infantil em 1999, no Estado de São Paulo. Através da comparação das tabulações por causas básicas e por causas múltiplas observou-se, através da razão M/ $B$, que grande parte da informação sobre causa do óbito é perdida em uma análise exclusiva por causas básicas. Os transtornos relacionados ao crescimento fetal ou duração da gestação apresentaram razão M/B de 13,7 e foram, de longe, as causas que se 
mais se pôde captar através da análise segundo causas múltiplas em comparação com a análise segundo causas básicas. Mesmo no caso das malformações, que tiveram uma razão $\mathrm{M} / \mathrm{B}$ de apenas 1,2, justifica-se a análise segundo causas múltiplas. Em termos absolutos, esta seria a causa com menor perda de informações sob o enfoque de causas básicas. Mas, em termos relativos, esta causa estaria superestimada em relação às demais básicas, comparativamente à sua participação no total de causas múltiplas. De fato, estudos realizados no Brasil, desde a década de 70, vêm tornando clara a necessidade da incorporação do conceito de causas múltiplas na análise da mortalidade ${ }^{1,2,5-7}$.

Através do uso da técnica de componentes principais foi possível delinear padrões de morbi-mortalidade infantil utilizando-se as causas múltiplas de morte, que foram de grande valia na procura de padrões de interrelacionamentos de causas que, uma vez reiterados com freqüência, indicaram quais as causas que apareceram de forma conjunta. Desta forma, foi possível obter um panorama mais completo das enfermidades que acometeram esta população relativamente ao que seria possível obter se fosse utilizado unicamente o arcabouço de causas múltiplas de óbito, sem uma metodologia que visasse encontrar estes padrões de inter-relacionamento.

O primeiro componente, chamado de "pós-neonatais, infecciosas redutíveis", revela uma manifestação contundente de mortalidade por doenças infecto-contagiosas associadas às doenças do aparelho respiratório e características do período pósneonatal. Alie-se a essas causas outras tais como as desnutrições, que também aceleram ou antecedem o processo mórbido por estas causas e conduzem à morte. As infecções na criança desnutrida são muito freqüentes e não há infecção banal no desnutrido grave ${ }^{10}$. Desta forma, as associações encontradas não são inesperadas. Além disso, este componente mostra que essas causas não ocorrem em conjunto com as causas relativas ao período perinatal, como os transtornos relacionados ao crescimento fetal ou duração da gestação, sua maioria associada ao baixo peso ao nascer ou à prematuridade, e aos transtornos respiratórios e cardiovasculares do período perinatal. Esse tipo de associação entre estas causas é explicado pelo fato de que o recém-nascido de pré-termo possui um baixo nível de maturidade de seus órgãos e sistemas. Quanto maior este grau de imaturidade, mais instável é o sistema respiratório. Os recém-nascidos mais imaturos possuem baixos níveis de imunidade passiva e baixa capacidade de produção de anticorpos próprios em resposta a infecções ${ }^{11}$. Mas isto não significa que este componente contraste óbitos redutíveis e não-redutíveis, por duas razões: primeiro, nem todas as doenças infecciosas são de fácil controle e mesmo tratamento, e existem doenças infecciosas que são mais facilmente controladas por adequadas condições de saneamento e de habitação, e outras que podem ser evitadas por ação dos serviços de saúde, como as imuno-preveníveis e a sífilis congênita (passível de identificação e tratamento na gestação); segundo, causas como a prematuridade e a hipoxia e anoxia do feto e do recém-nascido, e a síndrome de angústia respiratória, podem ser reduzidas. Um exemplo é a atenção pré-natal, que atua tanto diretamente, pois um pré-natal adequado pode prevenir as infecções maternas que levam a um risco aumentado de prematuridade e hipoxia e anoxia intrauterina ${ }^{12}$, quanto indiretamente, minimizando o impacto das condições maternas, sociais e econômicas e comportamentais desfavoráveis. Além disso, a administração de corticosteróides antes do parto pode acelerar o desenvolvimento pulmonar e reduzir o risco de síndrome de angústia respiratória do recém-nascido em cerca de $50 \%{ }^{13}$. A síndrome do desconforto respiratório é em muitos casos decorrente da própria imaturidade, sendo esta a razão da elevada associação de causas encontrada.

Na verdade, a prematuridade decorre de complexos mecanismos biológicos e de sua interação com fatores sociais, econômicos e comportamentais de difícil controle. É possível reduzir a prevalência da prematuridade, 
mas não é possível eliminá-la, mesmo em países desenvolvidos com amplo acesso a serviços de saúde ${ }^{14-16}$.

As causas externas de morbidade e de mortalidade, e as lesões e envenenamentos e conseqüências de causas externas, constituem outro grupo. Como as anomalias congênitas também fazem parte da constituição deste componente, a idéia é que pelo menos parte desses óbitos foi conseqüência de uma intervenção cirúrgica, muito possivelmente devido a uma malformação congênita que requeria tal intervenção. Poderse-ia atuar na prevenção das infecções maternas e hospitalares, que podem concorrer para as complicações pós-operatórias, para evitar que uma criança já desfavorecida, por exemplo, com uma anomalia congênita, tivesse seu prognóstico piorado em função de uma causa redutível, que nestas condições poderia ser fatal.

No que se refere ao terceiro componente, as infecções perinatais estão na base deste componente, associadas aos transtornos do aparelho digestivo do feto e do recémnascido e aos transtornos hematológicos e hemorrágicos do feto e do recém-nascido, entre outras causas de morte específicas do período perinatal. O fato das infecções perinatais estarem associadas a tantas outras causas de óbito perinatais refere-se ao fato de que uma série de distúrbios requer que o recém-nascido permaneça em unidades de terapia intensiva (UTI), tais como a própria prematuridade, alguns distúrbios cerebrais, pós-cirurgias de coração e doenças hemolíticas que requerem transfusão ${ }^{11}$. Muitas das infecções são adquiridas no próprio hospital, relacionadas com contatos humanos e equipamentos contaminados. Esta contaminação se deve a procedimentos invasivos que facilitam a colonização de bactérias ${ }^{13}$. Mesmo os recém-nascidos a termo são mais vulneráveis a bactérias, vírus e fungos do que as crianças acima de um ano de idade, porque seu sistema imunológico é mais imaturo. Infecções agudas mais severas são mais comuns porque a imaturidade da resposta imunológica permite que as infecções se espalhem rapidamente e que sejam mais letais.

\section{Conclusão}

As causas de morte podem ser estudadas segundo causas básicas ou segundo causas múltiplas. Neste trabalho, comparou-se as duas formas de análise. Os resultados substantivos mais importantes dizem respeito à conclusão de que baixo peso, imaturidade e suas complicações são a causa agregada mais comum na mortalidade infantil em São Paulo no final da década de 90. As causas externas vêm tendo importância mesmo na mortalidade de menores de um ano. Além disso, note-se que complicações do período perinatal não ligadas ao baixo peso e/ou à imaturidade também são causas relevantes de óbito neste período.

Em termos metodológicos, utilizou-se a análise de componentes principais a fim de se sistematizar as causas múltiplas de morte em conjuntos de enfermidades. Isto permitiu analisá-las procurando-se entender como se associavam entre si, desdobrandose em manifestações de doenças que conduziram à morte. Entende-se então que a análise por causas múltiplas permite, dessa forma recuperar, pelo menos parcialmente, a história natural das doenças ${ }^{6}$. A diferença entre esta análise e uma análise isolada de cada causa de morte é que foi possível observar com mais clareza e simplicidade os conjuntos de enfermidades que levaram ao óbito, o que, para fins de Saúde Pública, é mais elucidativo, dado que uma determinada confluência de doenças é capaz de tornar claras as diversas fases da causação destas e da morte. Conhecidas estas etapas, tornamse claras as medidas a serem tomadas para 0 mais possível, evitar o óbito. 


\section{Referências}

1. Santo AH, Laurenti R. Estatísticas de mortalidade por causas múltiplas: novas perspectivas com o sistema ACME. Rev Saúde Pública 1986; 20: 397-400.

2. Ferreira CEC, Saad, PM. Infant mortality by multiple causes: some examples from the vital statistics system in São Paulo State, Brazil. In: Anais do Seminário Internacional dos Centros Colaboradores da OMS para Classificação de Doenças. São Paulo; 1986. 12 p.

3. Speizer FE, Trey C, Parker P. The uses of multiple cause of death data to clarify changing patterns of cirrhosis mortality in Massachusetts. Am J Public Health 1977; 67: 333-6.

4. Manton KG, Stallard E. Recent trends in mortality analysis. Orlando: Academic Press; 1984.

5. Laurenti R. Causas Múltiplas de Morte. [tese de livre docência ] São Paulo: Faculdade de Saúde Pública da USP; 1973.

6. Santo AH, Pinheiro CE, Jordani MS. Causas básicas e associadas de morte por Aids, Estado de São Paulo, Brasil, 1998. Rev Saúde Pública 2000; 34: 581-8.

7. Santo AH, Pinheiro CE and Jordani MS. Causas múltiplas de morte relacionadas à tuberculose no Estado de São Paulo, 1998. Rev Saúde Pública 2003; 37: 714-21.

8. Dunteman GH. Principal Components Analysis. Newbury Park: Sage Publications; 1989.
9. Fleck MP, Bourdel MC. Método de simulação e escolha de fatores na análise dos principais components. Rev Saúde Pública 1998; 32: 267-72.

10. Murahovski, J. Desnutrição protéico-calórica. In: Murahovski J. Pediatria: diagnóstico + tratamento. São Paulo: Sarvier; 1982. p. 191-6.

11. Johnston PGB. The newborn child. New York: Churchill Livingstone; 1998.

12. Pascual JM, Koenigsberger MR. Parálisis cerebral: factores de riesgo prenatales Rev Neurol 2003; 37: 27580 .

13. Freddi, NA. Septicemia e meningite do rn. In: Segre CAM. RN. São Paulo: Sarvier; 1985. p. 286-9.

14. Moutquin JM. Classification and heterogeneity of preterm birth. BJOG 2003; 110 Suppl 20: 30-3.

15. Connon AF. An assessment of key aetiological factors associated with preterm birth and perinatal mortality. Aust N Z J Obstet Gynaecol 1992; 32: 200-3.

16. Lumley J. Defining the problem: the epidemiology of preterm birth. BJOG 2003; 110 Suppl 20: 3-7.

recebido em: 22/09/2003

versão final reapresentada em: 27/01/2004 aprovado em: 29/01/2004 